\title{
Immediate effect of passive static stretching versus resistance exercises on postprandial blood sugar levels in type 2 diabetes mellitus: a randomized clinical trial
}

\author{
Peeyoosha Gurudut', Abey P. Rajan ${ }^{2, *}$ \\ 'Department of Orthopaedics Physiotherapy, KLEU Institute of Physiotherapy, Belagavi, India \\ ${ }^{2}$ KLEU Institute of Physiotherapy, Belagavi, India
}

The prevalence of diabetes is rapidly rising all over the globe at an alarming rate. In India, more than 61.3 million people have been presently diagnosed with type 2 diabetes mellitus. It is possible to control the circulating blood glucose levels by reducing life style risk factors through physical activities comprising of muscle stretches, aerobic training, resistance exercises (REs), yoga, etc. The aim of this study is to identify and compare the immediate effect of passive static stretching (PSS) versus RE on blood glucose level in individuals with type 2 diabetes mellitus. The present study included 51 participants between the age of 40-65 years with type 2 diabetes mellitus, to study the immediate effect of 60-min PSS $(n=25)$ and 60 -min RE $(n=26)$. The outcome measure was blood glucose level which was checked by glucometer (freestyle neo). Blood sugar was assessed at 3 points of time that included fasting blood sugar level, $2 \mathrm{hr}$ after the meal and immediately after the exercise regimen. Results of this study showed significant reduction in blood glucose level in subjects according to glucometer with PSS $(P=0.000)$ and $\operatorname{RE}(P=0.00)$. However, both groups demonstrated equal effect in terms of lowering blood sugar level immediately after the exercise. The conclusion is both PSS and RE are effective in reducing postprandial blood glucose level in type 2 diabetes mellitus and must be prescribed for the patients who demonstrate difficulty in controlling post prandial spike.

Keywords: Type 2 diabetes mellitus, Exercise prescription, Resistance exercise, Passive stretching, Blood glucose level

\section{INTRODUCTION}

Diabetes mellitus (DM) is characterized by chronic hyperglycaemia with disturbances of carbohydrate, fat and protein metabolism resulting from defects in insulin secretion, insulin action or both. The effects of DM include long-term damage, dysfunction and failure of various organs, especially the kidneys, eyes, heart and blood vessels (Khan et al., 2005). The prevalence of diabetes is rapidly rising all over the globe at an alarming rate. Diabetes is gaining the situation of a serious epidemic in India with more than 61.3 million diabetic individuals presently diagnosed with the disease (Kaveeshwar and Cornwall, 2014).

DM can be classified into two categories namely, type 1 and type 2. Type $1 \mathrm{DM}$ is also known as juvenile diabetes and it is a disease of absolute insulin deficiency characterized by beta cell failure. Type $2 \mathrm{DM}$ is also called as adult-onset diabetes, which involves relative insulin deficiency and is characterized by a combination of three main metabolic problems - decreased beta cell function with reduced insulin production, insulin resistance in the peripheral tissues, and increased hepatic glucose production. Among the people with diabetes, $90 \%$ to $95 \%$ have type $2 \mathrm{DM}$ (Oyos and Barkley, 2012).

There are various treatment options that are available for DM that include mainly oral and intra venous drugs. Recent literature has successfully proved that various physical activities and exercises have an impact in reducing blood glucose levels (Oyos and Barkley, 2012). American College of Sports Medicine and American Diabetes Association recommend aerobic training for at least 150
*Corresponding author: Abey P. Rajan (iD https://orcid.org/0000-0002-4492-1130 KLEU Institute of Physiotherapy, Belagavi, 590010, Karnataka State, India Tel: +91-9731551708, E-mail: abeyabey93@gmail.com

Received: June 24, 2017 / Accepted: September 29, 2017
This is an Open Access article distributed under the terms of the Creative Commons Attribution Non-Commercial License (http://creativecommons.org/licenses/by-nc/4.0/) which permits unrestricted non-commercial use, distribution, and reproduction in any medium, provided the original work is properly cited. 
min per week and additionally resistance training at a minimum of 2-3 days per week parallel with pharmacology treatment (Park, 2015). It is possible to control circulating blood glucose levels by reducing life style risk factors through physical activities such as muscle stretching, aerobic training, yoga, resistance exercises (REs), etc. by improving tissue sensitivity to insulin (Mårdberg and Hasselgren, 2014; Metgud and Tamboli, 2014; Nelson et al., 2011; Park, 2015). During exercise, glucose uptake in striated muscles increases remarkably thus strategically reducing glucose levels in the body (Canadian Diabetes Association Clinical Practice Guidelines Expert Committee et al., 2013; Cauza et al., 2005; Solomen et al., 2015).

Static stretching involves holding a muscle in a challenging but comfortable position for $30 \mathrm{sec}$ without moving the extremity during the stretch. It can be performed either actively or passively. Active stretching is performed by the subject independently whereas passive stretching involves a stretch applies by the therapist or any other external force. Static passive stretching may be more advantageous and beneficial for individuals with type $2 \mathrm{DM}$ who may not be able to perform regular physical activities due to secondary complications such as, neuropathies, hypertension, and limb amputation, etc. (Solomen et al., 2015). Passive static stretching (PSS) will cause sustained tension in the muscle through the external force applied. It effectively has the benefit of exercising without any physical stress. Previous studies have shown its benefit in increasing cellular glucose uptake thus it can be effectively prescribed in individuals with type 2 DM (Cheng and Kujala, 2012; Nelson et al., 2011; Park, 2015). A study was done to investigate the effect of twenty minutes of passive stretching in lowering blood glucose level and the study revealed that passive stretching is an effective intervention for reducing blood glucose level in individuals with type $2 \mathrm{DM}$ (Nelson et al., 2011).

$\mathrm{RE}$ is a physical activity involving brief repetitive exercise with weights, weight machines, resistance bands or own body weights (e.g., push-ups) to increase muscle strength (Canadian Diabetes Association Clinical Practice Guidelines Expert Committee et al., 2013; Solomen et al., 2015). Resistance training results in increased strength and enlarged muscle mass and has also been described to improve insulin sensitivity and glycaemic control (Colberg et al., 2010; Sigal et al., 2007). Various studies have already found that resistance training is a useful intervention to reduce blood glucose levels in type $2 \mathrm{DM}$ thus being an alternative form of exercise for individuals with type 2 DM (Thomas et al., 2006). A study was conducted to identify whether resistance training or aerobic exercise lowers glycosylated hemoglobin $\left(\mathrm{HbA}_{1 \mathrm{c}}\right)$ level in adults with type $2 \mathrm{DM}$ which concluded that $\mathrm{RE}$ has a better impact on $\mathrm{HbA}_{\mathrm{lc}}$ level in type $2 \mathrm{DM}$ (Sigal et al., 2007).

Ample scientific data exists where long term effects of different forms of exercises (for example 6 weeks, 8 weeks, 12 weeks of exercise training) demonstrated a strong positive reduction in $\mathrm{HbA}_{1 \mathrm{c}}$ values. However, the main problem with type $2 \mathrm{DM}$ patients includes a spike or sudden rise of blood sugar levels $1-2 \mathrm{hr}$ postprandial. There is a need to the study the effect of exercises during this postprandial period, whether it has any immediate effect in controlling the sudden spike of blood glucose level which can be determined by quantifying these levels before and after the exercise. To the best of the literature search we found a study proved the effect of 20 min of passive stretching in lowering glucose levels in an at risk population. However, there are no comparative studies to find out whether PSS or resistance training is more effective in immediate reduction of blood sugar level in postprandial period in patients with type $2 \mathrm{DM}$. Therefore, the present study was conducted to evaluate and compare the immediate effect of PSS versus RE on postprandial blood sugar level.

\section{MATERIALS AND METHODS}

\section{Study design and setting}

The study was a double-blinded randomized controlled trial. The assessor who assessed for blood sugar level was blinded from the group to which subject was allotted and the therapist who gave intervention was blinded from the values of outcome measure. The study was conducted at a tertiary care centre in Belagavi city, Karnataka, India. Ethical clearance was obtained from the Institutional Ethical Committee. A written informed consent was taken from the subjects before the intervention.

\section{Sampling technique}

A total of 83 participants with known cases of diabetes were assessed for eligibility to participate in the study. Fifty-one subjects who met the inclusion and exclusion criteria were randomly assigned with concealed allocation to one of the treatment groups: PSS group ( $n=25)$ and RE group $(n=26)$ (Fig. 1). The subjects randomly chose one of the two labelled and sealed envelopes to determine their group allocation. The sample size was calculated using formula $\mathrm{n}=2(\mathrm{z} \alpha+\mathrm{z} \beta)^{2} \times \mathrm{S}^{2} / \mathrm{d}^{2}$, where $\mathrm{z} \alpha$ is $\mathrm{z}$ value for $\alpha$ error that is $1.96, z \beta$ is 0.84 with power $80 \% . S^{2}$ is the average standard deviation of blood sugar level form the reference article and $\mathrm{d}$ is the mean difference from the reference article. 


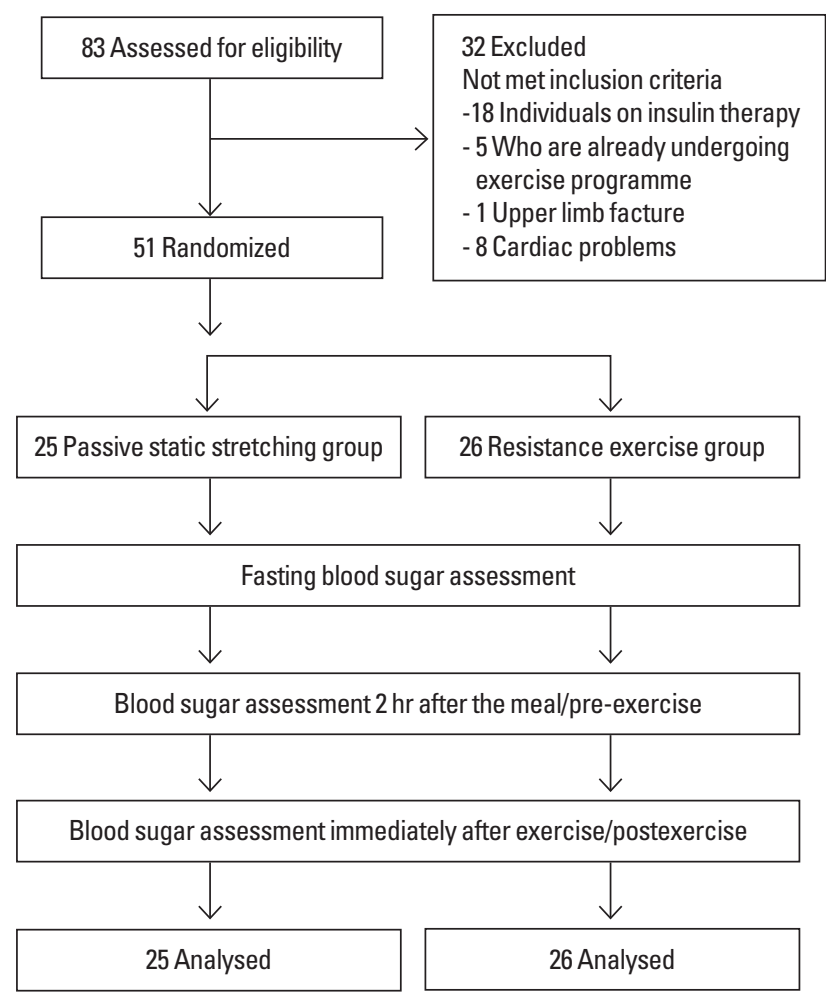

Fig. 1. Flow diagram of the study.

\section{Participants}

This interventional study included 51 subjects (a) between the age group of 40-65 years (b) diagnosed with type $2 \mathrm{DM}$ for more than 4 years (c) who were on oral hypoglycaemic drugs (d) who have sedentary lifestyle, and (e) had recent baseline $\mathrm{HbA}_{\mathrm{lc}}$ value of greater than $6.6 \%$. The study excluded subjects with (a) restricted physical activity due to any recent fractures of the limb, (b) pre-existing disease or medical condition that made their participation inadvisable, and (c) those who were undergoing insulin therapy or any exercise program.

\section{Outcome measure}

Blood sugar level was analysed using a hand held glucometer from a finger prick drop of blood. The assessment of blood sugar levels was done three times for each subject during the study. Firstly, values were obtained for fasting blood sugar (FBS) levels/baseline, then $2 \mathrm{hr}$ after the meal (postprandial) i.e., pre-exercise level and lastly immediately after the regimen/postexercise level (60 min).

\section{Intervention}

The subjects in PSS and RE groups were assessed for fasting blood glucose level using a glucometer (Freestyle Neo) and the exercise regimen was carried out $2 \mathrm{hr}$ after the meal according to their allocated group. Pre- and postexercise blood glucose levels were measured and documented. The exercise regimen consisted of 10-min warm up phase, 40-min intervention phase and $10 \mathrm{~min}$ of cool down phase. The muscle groups targeted for intervention were same in both the groups to avoid confounding factor if any.

PSS was performed as previous method (Nelson et al., 2011; Park, 2015).

The interventions were carried out on four muscles of the upper body and lower body bilaterally which included Trapezius, Biceps brachii, Triceps brachii, Pectoralis Major and Quadriceps, Hamstrings, Calf muscles, Glutei respectively. PSS was performed with 30-sec hold and 10-sec rest period. In each instance, the therapist received verbal acknowledgement about the stretch felt by the participants.

RE was performed as previous method (Cheng and Kujala, 2012; National Strength and Conditioning Association, 2008).

REs were performed with weight machines, dumbbells and theraband. The intensity of resistance was determined by testing the 10-repetition maximum of each subject. Accordingly, the subjects were asked to perform three sets of the exercise with 10 repetitions per set along with a rest period of $30 \mathrm{sec}$ between the sets for each muscle. The muscles selected for the exercise were similar to the stretching group.

\section{Statistical analysis}

The statistical analysis was done by using IBM SPSS Statistics ver. 23.0 (IBM Co., Armonk, NY, USA). Normality of the data was checked by using Shaprio-Wilk test, which indicated the data follows normal distribution with $95 \%$ of confidence. Hence, the parametric test of significance of paired sample $t$-test was performed for intra- and intergroup comparisons. Descriptive analysis was used to calculate mean and standard deviation. Value of $P<0.05$ was considered statistically significant at $5 \%$ level of significance.

\section{RESULTS}

In the present study, 51 subjects who were eligible participated in the study. Twenty-five subjects underwent PSS whereas 26 underwent resistance training.

There was no statistically significant difference observed in the demographic characteristics (Table 1). The baseline FBS level and $\mathrm{HbA}_{1 \mathrm{c}}$ values indicate fair to poor control of diabetes in all the subjects. The body mass index (BMI) of the subjects also shows to be on higher side, which indicates the subjects to fall under obese 
Table 1. Demographic characteristics of participants

\begin{tabular}{lcc}
\hline Variable & PSS group $(\mathrm{n}=25)$ & RE group $(\mathrm{n}=26)$ \\
\hline Age $(\mathrm{yr})$ & $55.36 \pm 7.02$ & $52.34 \pm 6.36$ \\
Height $(\mathrm{m})$ & $1.61 \pm 0.09$ & $1.62 \pm 0.13$ \\
Weight $(\mathrm{kg})$ & $71.32 \pm 8.94$ & $75.07 \pm 12.14$ \\
$\mathrm{BMl}\left(\mathrm{kg} / \mathrm{m}^{2}\right)$ & $27.55 \pm 2.91$ & $28.66 \pm 3.88$ \\
$\mathrm{HbA}_{1 \mathrm{c}}(\%)$ & $8.21 \pm 1.35$ & $8.90 \pm 1.27$ \\
\hline
\end{tabular}

Values are presented as mean \pm standard deviation.

PSS, passive static stretching; $\mathrm{RE}$, resistance exercise; $\mathrm{HbA}_{1 \mathrm{c}}$, glycosylated hemoglobin.

Table 2. Pair wise comparison of blood sugar level for passive static stretching group

\begin{tabular}{lcccc}
\hline Pair wise comparison & Mean \pm SD & $95 \% \mathrm{Cl}$ & t-value & $P$-value \\
\hline PR.EX and PO.EX. & $32.32 \pm 25.83$ & 21.65 to 42.98 & 6.25 & $0.000^{*}$ \\
FBS and PR.EX. & $44.96 \pm 25.02$ & -55.29 to -34.62 & -8.90 & $0.000^{*}$ \\
FBS and PO.EX. & $12.64 \pm 24.45$ & -22.73 to -2.54 & -2.58 & 0.016
\end{tabular}

SD, standard deviation; $\mathrm{Cl}$, confidence interval; PR.EX, pre-exercise; PO.EX, postexercise; FBS, fasting blood sugar.

${ }^{*} P<0.05$, statistical significance.

Table 3. Pair wise comparison of blood sugar level for resistance exercise group

\begin{tabular}{lcccc}
\hline Pair wise comparison & Mean \pm SD & $95 \%$ Cl & tvalue & $P$-value \\
\hline PR.EX. and PO.EX. & $53.53 \pm 24.45$ & 43.65 to 63.41 & 11.16 & $0.000^{*}$ \\
FBS and PR.EX. & $53.42 \pm 28.28$ & -64.84 to -41.99 & -9.63 & $0.000^{*}$ \\
FBS and PO.EX & $0.11 \pm 20.53$ & -8.17 to 8.40 & 0.029 & 0.977 \\
\hline
\end{tabular}

$\mathrm{SD}$, standard deviation; $\mathrm{Cl}$, confidence interval; PR.EX, pre-exercise; PO.EX, postexercise; FBS, fasting blood sugar.

${ }^{*} P<0.05$, statistical significance.

Table 4. Between group analysis of blood sugar level

\begin{tabular}{lccc}
\hline Variable & PSS group $(n=25)$ & RE group $(n=26)$ & $P$-value \\
\hline Fasting blood sugar level & $205.44 \pm 44.39$ & $212.57 \pm 38.01$ & 0.54 \\
Pre-exercise (postprandial) & $250.40 \pm 51.69$ & $266.00 \pm 51.55$ & 0.28 \\
Postexercise (immediately after exercise) & $218.08 \pm 47.08$ & $212.46 \pm 42.99$ & 0.65 \\
\hline
\end{tabular}

Values are presented as mean \pm standard deviation.

PSS, passive static stretching; $\mathrm{RE}$, resistance exercise.

class according to World Health Organization classification.

On pair wise comparison for both the groups, blood sugar levels demonstrated statistical significant difference between FBS level and postprandial/pre-exercise $(P<0.000)$. Thus, it can be inferred that the blood sugar levels had increased significantly $2 \mathrm{hr}$ after the meal or pre-exercise levels compared to FBS values. Further, the results revealed significant difference between postprandial/ pre- and postexercise blood sugar levels $(P<0.000)$ which means after the exercise the blood sugar levels significantly dropped. However, the comparison of blood sugar levels between fasting and postexercise values, results showed no statistical significance, which indicates that the drop or decrease in blood sugar levels due to exercises, came almost close to FBS values (Tables 2, 3).
However, on between group or intergroup comparison no statistical significance was observed for blood sugar level. In the PSS group, a mean difference of $32 \mathrm{mg} / \mathrm{dL}$ was found pre- and postexercise indicating that PSS effectively reduces blood sugar level in the postprandial period. In the RE group, a difference of $54 \mathrm{mg} /$ $\mathrm{dL}$ was noted. The blood glucose level postexercise, nearly dropped down to the FBS level indicating a larger difference between the mean values after performing REs (Table 4).

\section{DISCUSSION}

The present study aimed to find out the immediate effect of PSS versus REs on blood sugar levels in sedentary type $2 \mathrm{DM}$ pa- 
tients. The baseline demographic variables taken were age, height, weight, recent $\mathrm{HbA}_{1 \mathrm{c}}$ value and $\mathrm{BMI}$.

The demographic data of the present study showed that majority of the subjects had a higher BMI, that is, above $27 \mathrm{~kg} / \mathrm{m}^{2}$. Previous literatures state that the relationship between high BMI and DM is not absolute. It could depend on the presence of pathogenic adipose tissues, which may either cause obesity due to the existing metabolic disease or vice versa (Bays et al., 2007)

The mean value of $\mathrm{HbA}_{\mathrm{lc}}$ values in $\mathrm{RE}$ is relatively higher than the PSS group. Several studies revealed that PSS and RE are effective treatment in reducing blood sugar level. The current study was conducted to evaluate which treatment is more effective in reducing blood sugar level immediately.

According to a study by Park (2015), PSS of the skeletal muscle is an alternate to exercise which helps to regulate blood sugar level in diabetic patients. A study showed that passive stretching increases heat production and oxygen consumption in muscles. This leads to an increase in the metabolic activity in these muscles thus causing reduction in the blood glucose level due to the incorporation of glucose transporter type- 4 (GLUT- 4 ) into the stretched muscles. Stretching increases the level of nitric oxide by single passive stretch of $20 \%$. Nitric oxide also influences the incorporation of GLUT- 4 thus facilitating its activity. PSS is also known to alter the microcirculation thereby reducing tissue oxygen exchange. This resultant ischemia facilitates the translocation of GLUT- 4 into the sarcolemma. Additional related studies on PSS demonstrate an increase in glycogen breakdown at the cellular level and support the effectiveness of PSS in reducing blood sugar level by stimulating the activity of protein kinase B, further improving glucose uptake by the stretched muscle cells. These mechanisms provide a possible explanation to the positive effect of PSS on blood sugar level (Nelson et al., 2011; Park, 2015).

A study was conducted to compare the effects of active and passive stretching exercises in type $2 \mathrm{DM}$ patients. It concluded that passive stretching yielded better results than active stretching. This was probably due to the maintenance of a constant tension throughout the passive stretch as compared to the active stretch. The tension produced, increased the metabolic activity of the muscles thereby reducing blood glucose level by the mechanism mentioned above (Solomen et al., 2015). Another study was conducted to analyse the effect of twenty minutes PSS in a similar target population by comparing two groups. The first group underwent PSS whereas the second group underwent mock PSS i.e., no tension was applied to the muscle. This study concluded that PSS is an effective intervention in reducing blood sugar level in individuals with type $2 \mathrm{DM}$ (Nelson et al., 2011)

The present study indicates that RE is an effective intervention in immediately reducing blood glucose level in this population. A systematic review on effect of resistance training in patients with type 2 DM in 2014 which supports the use of resistance training for improving glycaemic control (Mårdberg and Hasselgren, 2014). Another study in 2005 on relative benefits of endurance and strength training on the metabolic factors and muscle function of people with type $2 \mathrm{DM}$ reported that there was a significant reduction of $\mathrm{HbA}_{\mathrm{lc}}$ value in resistance training group as compared to aerobic training group (Cauza et al., 2005).

There could be various possible explanations to this outcome. Firstly, type $2 \mathrm{DM}$ is known to occur due to a pathological decrease in the number of beta cells in the liver leading to increased blood glucose level (Donath et al., 2005; Inzucchi and Sherwin, 2011). A study has proved significant effects of RE in improving beta cell function (Eriksson et al., 1991; Nieuwoudt et al., 2017). Secondly, previous studies have stated that RE causes changes in the metabolic activity due to increased heat production and oxygen consumption by the skeletal muscles (Nelson et al., 2011; Eves and Plotnikoff, 2006). These exercises can increase the expression of protein kinase $\mathrm{B}$, thereby improving the insulin-signalling pathway. This further leads to the regulation of GLUT-4 activity, increasing its translocation at the cellular level (Cheng and Kujala, 2012; Holten et al., 2004). Thirdly, scientific literature has determined that RE can increase the rate of glucose uptake by skeletal muscles upto 7-20 times more than the basal level, depending on the intensity of the exercise (Messina et al., 2015). Finally, RE is known to increase muscle insulin sensitivity in the postexercise period, thereby improving glycaemic control in individuals with type 2 DM (Cheng and Kujala, 2012). A study by Perseghin et al. (1996) found that exercise increases insulin-dependent glucose transport and hexokinase II activity.

According to the results of the present study, both the groups show equal reduction in blood sugar level after the exercise regimen. This equal effectiveness could be attributed to the fact that both forms of exercises have similar mechanisms of reduction in blood glucose levels in both forms of exercises. This may be the reason for the immediate effect of both the intervention methods in reducing blood sugar level in patients with type $2 \mathrm{DM}$. However, according to the mean difference values of blood sugar at post exercise (Tables 2,3 ) demonstrates slightly greater reduction with REs ( $54 \mathrm{mg}$ ) than passive stretching exercises $(32 \mathrm{mg}$ ) which is although not statistically significant but might be clinically significant. However, the literature that indicates how much of 
reduction in blood sugar level that can be termed, as clinically significant difference is lacking and unclear.

The postprandial spike in blood sugar is always a difficult thing for the patients to manage and control. In the present study blood sugar levels demonstrated statistical significant difference between FBS level and postprandial/pre-exercise blood sugar levels $(P<0.000)$. A study was conducted which suggests spike in the blood sugar level at 1-2 hr of postprandial period (Monnier et al., 2003). Hence, in the present study exercise session was scheduled at $2 \mathrm{hr}$ after meals in order to evaluate effect of exercise intervention at postprandial time. Although suggestions are given to do light exercises immediately after meals there is lack of literature, which proves this effect of exercise. Previous literature have studied long-term effects of exercises on blood sugar levels. However, there are no studies, which assess effect of exercise intervention at $2 \mathrm{hr}$ after the meal to abate the postprandial spike.

The present study had a few limitations. Due to the time constraint for study conducted, immediate effect of exercise was compared and long-term effects were not studied. $\mathrm{HbA}_{\mathrm{lc}}$ was not assessed postexercise because the study was aimed on the immediate effect of exercises and $\mathrm{HbA}_{\mathrm{lc}}$ is ideally checked every 2 to 3 months.

A prospective study could be taken up to evaluate the long-term effects of the exercises specifically during the postprandial period. A similar study can be done to evaluate the pre- and posteffects of exercise interventions on the $\mathrm{HbA}_{\mathrm{lc}}$ test and glucose tolerance tests values. This study can also be repeated by using a different target population such as patients with hypertension or other metabolic conditions with comparisons of different forms of exercises.

Hence, the present study concluded that both PSS and REs are equally beneficial interventions in reducing postprandial blood glucose level that was close to FBS levels, immediately after exercise in subjects with type 2 DM. Further, PSS can be of advantage for patients who are bed ridden and who cannot perform movements actively whereas REs are suitable for patients who are relatively young and have no associated comorbid conditions (e.g., hypertention, cardiac problems). Both RE and PSS are effective interventions that can be prescribed specifically at post prandial stage i.e., $2 \mathrm{hr}$ after the meal for diabetic individuals who have problem or difficulty in controlling the postprandial spike in blood sugar.

\section{CONFLICT OF INTEREST}

No potential conflict of interest relevant to this article was reported.

\section{REFERENCES}

Bays HE, Chapman RH, Grandy S; SHIELD Investigators' Group. The relationship of body mass index to diabetes mellitus, hypertension and dyslipidaemia: comparison of data from two national surveys. Int J Clin Pract 2007;61:737-747.

Canadian Diabetes Association Clinical Practice Guidelines Expert Committee, Sigal RJ, Armstrong MJ, Colby P, Kenny GP, Plotnikoff RC, Reichert SM, Riddell MC. Physical activity and diabetes. Can J Diabetes 2013;37 Suppl 1:S40-44.

Cauza E, Hanusch-Enserer U, Strasser B, Ludvik B, Metz-Schimmerl S, Pacini G, Wagner O, Georg P, Prager R, Kostner K, Dunky A, Haber P. The relative benefits of endurance and strength training on the metabolic factors and muscle function of people with type 2 diabetes mellitus. Arch Phys Med Rehabil 2005;86:1527-1533.

Cheng S, Kujala UM. Exercise in type 2 diabetes: the mechanisms of resistance and endurance training. J Sport Health Sci 2012;1:65-66.

Colberg SR, Sigal RJ, Fernhall B, Regensteiner JG, Blissmer BJ, Rubin RR, Chasan-Taber L, Albright AL, Braun B; American College of Sports Medicine; American Diabetes Association. Exercise and type 2 diabetes: the American College of Sports Medicine and the American Diabetes Association: joint position statement executive summary. Diabetes Care 2010;33:2692-2696.

Donath MY, Ehses JA, Maedler K, Schumann DM, Ellingsgaard H, Eppler E, Reinecke M. Mechanisms of $\beta$-cell death in type 2 diabetes. Diabetes 2005;54(suppl 2):S108-113.

Eriksson KF, Lindgärde F. Prevention of type 2 (non-insulin-dependent) diabetes mellitus by diet and physical exercise. The 6-year Malmö feasibility study. Diabetologia 1991;34:891-898.

Eves ND, Plotnikoff RC. Resistance training and type 2 diabetes: Considerations for implementation at the population level. Diabetes Care 2006;29:1933-1941.

Holten MK, Zacho M, Gaster M, Juel C, Wojtaszewski JF, Dela F. Strength training increases insulin-mediated glucose uptake, GLUT4 content, and insulin signaling in skeletal muscle in patients with type 2 diabetes. Diabetes 2004;53:294-305.

Inzucchi SE, Sherwin RS. Type 2 diabetes mellitus. Cecil Medicine. 24th ed. Philadelphia (PA): Saunders Elsevier; 2011.

Kaveeshwar SA, Cornwall J. The current state of diabetes mellitus in India. Australas Med J 2014;7:45-48.

Khan RC, Weir GC, King LG, Jacobson AM, Moses AC, Smith RJ, editors. Joslin's diabetes mellitus. 14th ed. Philadelphia (PA): Lippincott Williams and Wilkins: 2005.

Mårdberg E, Hasselgren M. Effect of resistance training in patients with type 2 diabetes mellitus - A systematic review [dissertation]. Orebo: 
Örebro University School of Medicine; 2014.

Messina G, Palmieri F, Monda V, Messina A, Dalia C, Viggiano A, Tafuri D, Messina A, Moscatelli F, Valenzano A, Cibelli G, Chieffi S, Monda M. Exercise causes muscle GLUT4 translocation in an insulin-independent manner. Biol Med (Aligarh) 2015;S3:007.

Metgud SC, Tamboli AV. Efficacy of passive sustained specific muscle stretch on patients with type-2 diabetes mellitus: a randomized control trial. Rom J Phys Ther 2014;20:41-45.

Monnier L, Lapinski H, Colette C. Contributions of fasting and postprandial plasma glucose increments to the overall diurnal hyperglycemia of type 2 diabetic patients: variations with increasing levels of $\mathrm{HbA1c}$. Diabetes Care 2003;26:881-885.

National Strength and Conditioning Association. Exercise technique manual for resistance training. 2nd ed. Champaign (IL): Human Kinetics; 2008.

Nelson AG, Kokkonen J, Arnall DA. Twenty minutes of passive stretching lowers glucose levels in an at-risk population: an experimental study. J Physiother 2011;57:173-178.

Nieuwoudt S, Fealy CE, Foucher JA, Scelsi AR, Malin SK, Pagadala M,

Rocco M, Burguera B, Kirwan JP. Functional high-intensity training improves pancreatic $\beta$-cell function in adults with type 2 diabetes. Am J Physiol Endocrinol Metab 2017;313:E314-320.

Oyos ML, Barkley S. Diabetes medications: guidelines for exercise safety. ACSM'S Certified News 2012;22:6-10.

Park SH. Effects of passive static stretching on blood glucose levels in patients with type 2 diabetes mellitus. J Phys Ther Sci 2015;27:1463-1465.

Perseghin G, Price TB, Petersen KF, Roden M, Cline GW, Gerow K, Rothman DL, Shulman GI. Increased glucose transport-phosphorylation and muscle glycogen synthesis after exercise training in insulin-resistant subjects. N Engl J Med 1996;335:1357-1362.

Sigal RJ, Kenny GP, Boulé NG, Wells GA, Prud'homme D, Fortier M, Reid RD, Tulloch H, Coyle D, Phillips P, Jennings A, Jaffey J. Effects of aerobic training, resistance training, or both on glycemic control in type 2 diabetes: a randomized trial. Ann Intern Med 2007;147:357-369.

Solomen S, Shakya R, Agarwal K, Aaron P, Pradeep S. Passive stretching versus active stretching on immediate blood glucose in subjects with type II Diabetes Mellitus: A pilot study. Int J Phys Edu Sports Health. 2015;2:146-149.

Thomas DE, Elliott EJ, Naughton GA. Exercise for type 2 diabetes mellitus. Cochrane Database Syst Rev 2006;(3):CD002968. 